\title{
Using Participatory Approaches to Enhance Women's Engagement in Natural Resource Management in Northern Ghana
}

\author{
Peter Cronkleton ${ }^{1, *(\mathbb{D}}$, Kristen Evans ${ }^{1}$, Thomas Addoah ${ }^{1}$, Emilie Smith Dumont ${ }^{2}$, Mathurin Zida ${ }^{1}$ \\ and Houria Djoudi ${ }^{1}$
}

1 Sustainable Landscapes and Livelihoods Team, Center for International Forestry Research, Jalan CIFOR, Situ Gede, Bogor Barat 16115, Indonesia; kristenannevans@gmail.com (K.E.); addoahthomas@gmail.com (T.A.); M.Zida@cgiar.org (M.Z.); H.Djoudi@cgiar.org (H.D.)

2 Resilient Livelihood Systems Team, World Agroforestry Centre, Nairobi 00100, Kenya; emilie.smith.dumont@gmail.com

* Correspondence: p.cronkleton@cgiar.org

Citation: Cronkleton, P.; Evans, K.; Addoah, T.; Smith Dumont, E.; Zida, M.; Djoudi, H. Using Participatory Approaches to Enhance Women's Engagement in Natural Resource Management in Northern Ghana. Sustainability 2021, 13, 7072.

https://doi.org/10.3390/su13137072

Academic Editor: Tasos Hovardas

Received: 23 January 2021

Accepted: 10 June 2021

Published: 23 June 2021

Publisher's Note: MDPI stays neutral with regard to jurisdictional claims in published maps and institutional affiliations.

Copyright: (c) 2021 by the authors. Licensee MDPI, Basel, Switzerland. This article is an open access article distributed under the terms and conditions of the Creative Commons Attribution (CC BY) license (https:// creativecommons.org/licenses/by/ $4.0 /)$.

\begin{abstract}
From 2016-2019, the West African Forest-Farm Interface (WAFFI) project engaged with smallholder farmers in northern Ghana to explore mechanisms to improve the influence of underrepresented peoples, particularly women, in decision-making processes and platforms that affect their access to natural resources. Through a multi-phase process of participatory activities, including auto-appraisal, participatory action research (PAR) and facilitated knowledge exchange, villagers and researchers worked together to document and develop a better understanding of the challenges and changes facing women and men in the region to generate social learning. Among these challenges, the degradation of forest resources due to over exploitation, weak governance and conflict of use over shea trees (Vitellaria paradoxa) were particularly important for women. The WAFFI approach created a scaffold for social learning that strengthened the capacity of local stakeholders to share their perspectives and opinions more effectively in multi-stakeholder forums and dialogue related to resource use and land use change initiatives.
\end{abstract}

Keywords: social learning; Ghana; shea; participatory action research

\section{Introduction}

In the rural savanna landscapes of northern Ghana, the agro-silvopastoral systems used by smallholder households integrate trees, crops and livestock, blurring the distinction between agricultural land uses and forest and tree uses within natural resource management systems. The fuzzy boundaries between forests and farms that characterize these mosaic landscapes are typical in smallholder landscapes elsewhere [1,2]. Women play integral roles in these dryland semi-arid systems, particularly in the use, access to and management of trees, and some, including shea (Vitellaria paradoxa) are important components of women's livelihoods [3]. However, customary systems of land and tree tenure differentially constrain women's access to resources, while national policies do not acknowledge or support their roles as resource managers [4]. Local knowledge and views should play a crucial role in identifying issues emerging from opportunities and challenges in these systems.

Multi-stakeholder forums (MSFs) could assist policy makers to better understand these complex production systems and contribute to transformative actions [5]. MSFs take the form of meetings, roundtables, workshops or other platforms where diverse stakeholders share information and opinions, consult, develop policy or make decisions collaboratively [6]. However, ensuring that such fora include the perspectives of both women and men is crucial, and creating conditions in which women can share their resource management knowledge and experience is a challenge [5,7]. Multi-stakeholder 
forums can be intimidating spaces for newcomers or traditionally under-represented groups such as women $[5,8]$. In addition, cultural norms often ensure that the opinions of existing powerholders continue to dominate unless there are interventions by outside facilitators or institutions $[9,10]$.

A conventional strategy for promoting the greater inclusion of women, particularly rural women, in decision-making mechanisms has been to require their attendance or membership through quotas [11-13]. Quotas in forest management groups in Peru, Indonesia and Tanzania have generated positive conservation outcomes [11], and in India quotas in village councils improved the long-term educational aspirations of young women [12]. However, quotas can also meet stiff resistance in traditional male-dominated societies [14], resulting in pushback or workarounds that undermine progress to women's inclusion. Gender roles can be frustratingly "sticky", and top-down mandates alone are often not enough to generate the shifts in power relations that lead to improved influence in decision-making in MSFs [15]. While quotas provide leverage points for immediate action, deeper structures and causes of marginalization must be addressed to create pathways for transformation.

\section{Participatory Approaches and Social Learning}

We argue for a bottom-up approach whereby opinions, attitudes and frames of reference about gender are shifted and reframed at the individual and community levels through group learning processes known as social learning. We adopt the Keen et al. definition of social learning as collective reflection and action to improve management of social-ecological systems [16]. The core mechanism of social learning is a process of "iterative reflection" that occurs when experiences, ideas and environments are shared with others [16]. This process is often characterized as occurring in cycles [17], or loops [18,19], where conscious phases of group reflection are interspersed within the information collection processes [18]. Feedback on the process causes actors to reflect on and change their initial assumptions [20]. Further learning occurs when there is reflection on the process itself and the conditions that structure interactions and learning, i.e., "learning to learn". This type of multiple loop learning is described by Peschl [21] as a shift in frames of reference that changes the fundamental perspectives of the participants; this "reframing" causes the participants to step out of their own experiences and look at the situation as a whole in a reflective process. Multiple loop learning can incrementally yet fundamentally shift existing power relations to create the conditions where women can more effectively participate in group decision-making such as MSFs [22-25].

Social learning is central to adaptive collaborative approaches [26], such as participatory action research (PAR), a structured, learning-focused activity where people work together to solve common problems and answer shared questions [27]. In PAR activities, a group defines questions to be answered, gathers information related to that question, reflects on the results and then collectively decides on next steps [28]. Group learning processes such as PAR have demonstrated effectiveness at involving marginalized or under-represented groups, such as rural women, in problem-solving and knowledge creation [22-24]. The collaborative approaches utilized in PAR assist village stakeholders in evaluating local natural resource management systems and in identifying strategies that could encourage adaptive practices, improve sustainability or promote equity [20,28]. PAR can promote social learning by facilitating collective reflection and action to improve management of social-ecological systems $[16,27,29]$. Such participatory experimentation can catalyze adaptation through an experiential approach to learning, or "learning by doing" [30,31].

While social learning has drawn attention as a means to understand complex socioenvironmental systems and address problems collectively and democratically, there remains a lack of agreement as to whether social learning is a process, an outcome or a network [32] or how to evaluate whether it has occurred [33]. Reed et al. [34] argue that for social learning to occur, a process must meet three conditions: first, demonstrate a change in understanding among the individuals involved; second, that the change oc- 
curs in a wider social unit or community; and three, that the change in understanding occurs through social interactions or processes. Furthermore, there is a need to better understand how interventions relate to the contextual conditions where social learning occurred [32]. Scholz et al. [33] contend that participatory methods do not necessarily generate social learning and recommend pre- and post-testing to attribute social learning to participatory methods.

To that end, this paper analyzes efforts to use participatory methods to facilitate the engagement in dialogues of local producers, particularly women, to give voice to their priorities and frame debate around topics important for their livelihoods. We conceptualized engagement as a learning-based process of building participation, with an emphasis on active and interactive (empowering) participation, per Agarwal's typology of participation [35]. In practice, facilitating engagement meant creating opportunities where women were active participants, i.e., expressing opinions and taking initiative, as well as interactive (empowering) participants, meaning that women had increased voice and influence in the decision-making of the group. The participatory activities generated iterative cycles of local knowledge assessment and group learning that built on a stepwise process of observation, analysis, planned action, monitoring and reflection. These activities catalyzed dialogue on conflict of use problems related to shea (Vitellaria paradoxa), and other unintended consequences of resource degradation. We provide an example of how we operationalized participatory approaches including PAR and paired them with MSFs to improve the inclusion of women in stakeholder fora generating social learning processes over time. We present a description of the challenges facing community members, specifically women, in rural savanna landscapes in Ghana. We describe the participatory activities that we introduced, how the activities generated social learning outcomes and how those outcomes created conditions for better inclusion of women in MSF dialogues.

This work was conducted as part of the West Africa Forest Farm Interface (WAFFI) project implemented by CIFOR/ICRAF, Tree Aid and the Organization for Indigenous Initiatives and Sustainability (ORGIIS), a local NGO with funding by the International Fund for Agricultural Development (IFAD). The general objective of the WAFFI project was to identify practices and policy interventions that could improve the income and food security of rural smallholders in Burkina Faso and Ghana through integrated forest/tree management systems that are environmentally sound and socially equitable. The work presented in this paper addressed an underlying objective, which was to encourage grassroots dialogue and broad participation to build consensus around common issues and shared problems to strengthen the capacity of local people to ensure that their interests are addressed by decision makers. The WAFFI project's central objectives were not to test whether social learning occurred, and thus the gathering of information was not designed with that in mind; nevertheless, we observed processes of group learning that provide insights into the ways that participatory methods and social learning are linked, particularly to support women's participation. To that end, we used participatory approaches to facilitate smallholder involvement in the definition, analysis and evaluation of issues related to the management of these mosaic landscapes.

\section{Site Description}

The WAFFI project worked in two multi-village landscapes each surrounding six villages in Ghana and Burkina Faso, in a region of dry forest and savanna parklands between 2016 and 2019. This paper focuses on the work in Ghana. The six participating Ghanaian villages were in the Kassena-Nankana West District in the Upper East region (see Figure 1). The ethnicity of residents in the participating villages is primarily Kassena with some neighboring Fulani settlements. We do not have exact population figures for the villages, but a rapid census of the communities identified a total of 355 households, including both single and multifamily compounds. The villages ranged in size from 17 to 89 households, with an average of 59 households. Villages were purposefully selected by our local partner, ORGIIS, to represent villages in buffer zones near forest reserves. 


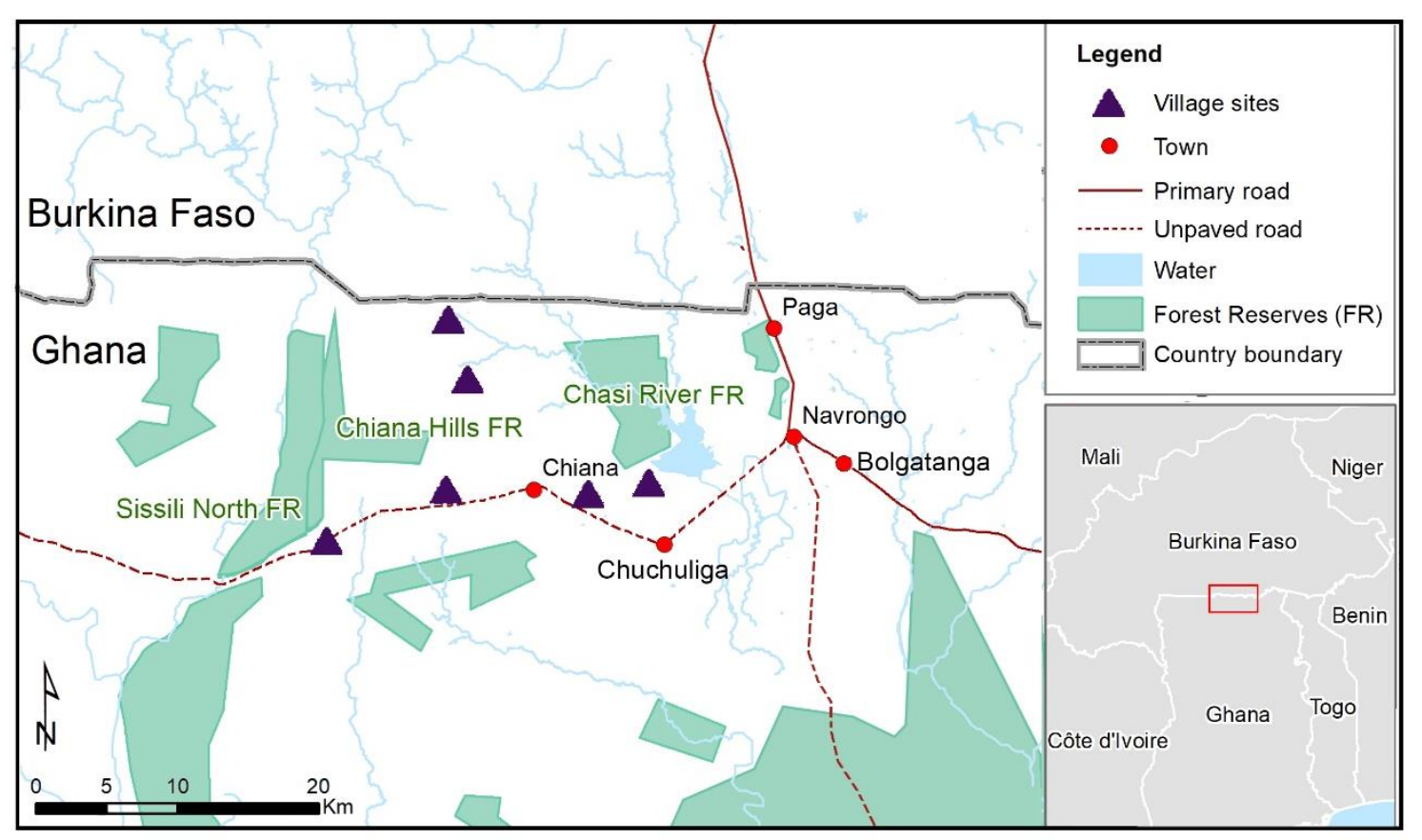

Figure 1. Map of the village sites in Ghana.

The land tenure systems at these sites are complex. In Ghana, the constitution recognizes a system of legal pluralism that privileges the jurisdiction of customary authorities over land [36]. In the Upper East region, traditional land priests known as a tindanas (or tigat $u$ in the local Kassena language) distribute land to resident families. Because village boundaries are informal, there is little information available on the total land areas of the villages.

Land is still mainly accessed through non-market based customary land tenure systems, and $98 \%$ of land parcels are distributed by the family or community members [37]. Women do not have the right to inherit family land, and they generally rely on male relatives, husbands, brothers or fathers to gain land access [38]. It is possible for certain women to cultivate and make management decisions on a separate plot. However, women's labor contributions on their husbands' farmland are substantial [39,40]. Traditionally, men are primarily responsible for providing the main sources of household livelihoods and women's land rights are regarded as secondary compared to the rights of their male relatives [37,41]. These intra-household repartition patterns determine broader decision-making processes and the control over household productive resources. As a result, most agricultural earnings are under the husband's control [40]. Women's participation in local governance structures is very low in general and absent in the most decisive structures, for instance town councils [42]. Those power imbalances partly explain the low inclusion of women in development initiatives, e.g., incentives for commercial crops or irrigation development programs. Female farmers in Ghana are less likely to adopt new agricultural practices due to limited access to resources including land, education and extension services [43]. However, as in other West African cultures, certain crops have more potential to address those gender gaps as they are traditionally classified as "feminine", particularly indigenous food trees species such as shea and African locust bean (Parkia biglobosa) [44]. These trees are crucial for women's income in northern Ghana as women prioritize their use to meet immediate needs such as food, schooling and healthcare [45].

Within these village landscapes, households depend on a diversity of trees and tree products including, among others, baobab (Adansonia digitata), locust bean (known locally as dawadawa) and shea. Shea is particularly important as a source for food, fuel and income for these families and collecting shea nut is primarily an activity done by women, and it is often an important part of women's livelihoods $[46,47]$. It is an indigenous, multi-use tree 
valued for its oil-rich nuts and is found across semi-arid zones of sub-Saharan Africa in forests and woodland commons, referred to here as parklands, and in fields managed as an agroforestry crop by farmers [48]. Different patterns of tree tenure apply to resources in each location. Customary property rights over land also extend to tree products from the trees found on farms; access is usually granted by the male head of household to wives or related women. Trees in parklands are functionally open access. The Ghanaian government maintains ownership of gazetted forest reserves and some irrigated lands [4]; while access is legally restricted, controls do not function well, so local people are able to harvest forest products opportunistically.

The management practices used by smallholders in this savanna landscape may offer a level of resiliency as farmers face emerging challenges; nonetheless, they are vulnerable to climate change, soil degradation, population increases and other environmental stressors $[45,49,50]$, and increasingly, shifts in global markets. In recent years, international demand for shea nut for cosmetics and confectionary products has driven up the market price [51]. As a result, men are increasingly entering the shea nut value chain and asserting more control over the shea nuts collected by women in their households [45].

\section{Methods}

From 2016 to 2018, we implemented a series of participatory methods to involve local men and women in the assessment of opportunities and challenges faced by rural producers in northern Ghana and to facilitate their participation in MSFs organized by the WAFFI project. The approach was intended to enhance engagement, which we observed not only in the number of participants in meetings and activities, but also when participants played active roles in making decisions and selecting the topics to address. As a rough rule of thumb, since participation was voluntary, topics that reflected local interest would likely attract more active involvement and participation.

The WAFFI participatory approach consisted of three nested activities to facilitate inclusion and build social learning processes: auto-appraisal, participatory action research (PAR) and exchange workshops held at the village and district level. See Figure 2 for a flowchart illustrating the sequence of activities. We describe these activities in more detail in the following paragraphs. At the start of activities, which involved trainings and meetings, villagers were informed that their participation was voluntary, that they had no obligation to attend and that they could cease involvement at any time. (Other components of the WAFFI project involving socio-economic research not covered in this paper, such as household survey and key informant interviews, included an informed consent statement that was read to all informants to obtain witnessed verbal agreement, due to low levels of literacy at sites, and all informants we left with a card listing contact information for CIFOR in Ghana and our regional office in Ouagadougou, Burkina Faso.) They were also informed that activities would take place in public and were intended to generate information on local perceptions of village conditions to share with neighboring communities. Village leaders were provided with contact information for CIFOR, ICRAF and Tree Aid in case questions arose about project activities.

Auto-appraisal is a structured assessment of local conditions, needs and opportunities conducted by local people [52]. It is similar to other methods such as rapid rural appraisal [53], although the key difference is that auto-appraisal is carried out by teams of community members trained as facilitators rather than external technicians. Auto-appraisal is a way of engaging community members to explore and document their context together. Facilitators from the community carry out a series of structured information-gathering activities that include sketch mapping, historic timelines for the community and group interviews to collect information on local social, human, financial, physical and natural capital [54]. Auto-appraisal produces an overview of community conditions based on local perceptions and expertise, but the primary goals are to initiate a process of reflection and discussion of shared interests and variable needs at the community level and to ex- 
pand engagement in the community so that residents can collectively prioritize topics of importance to them.
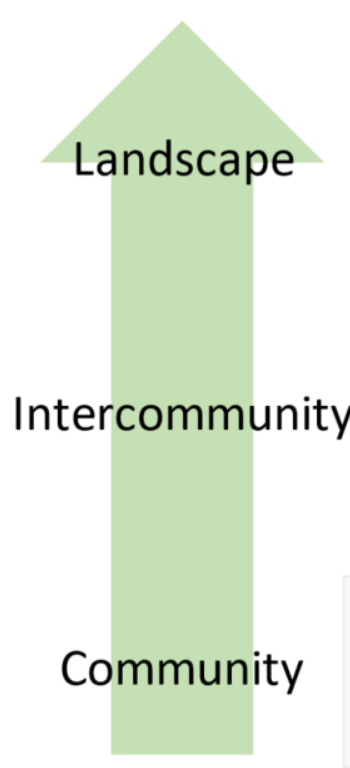

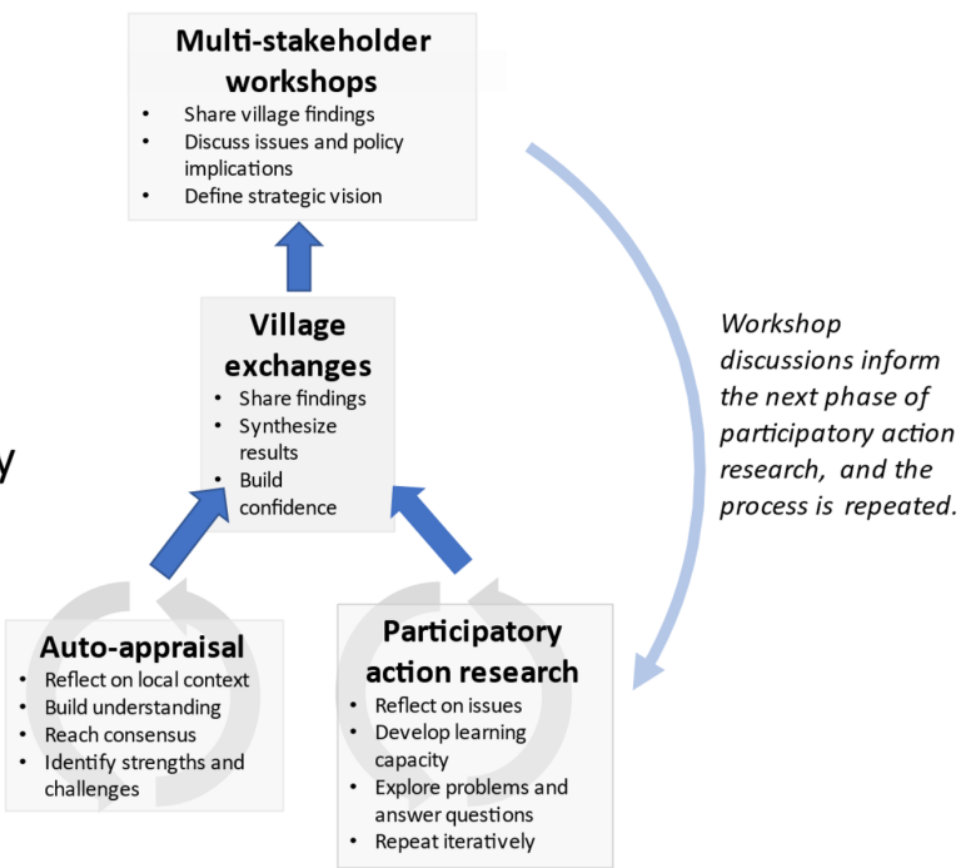

Figure 2. The participatory approach.

We initiated the auto-appraisal activity in November 2016 with a multi-day training workshop for village level facilitators in the regional capital, Bolgatanga. Participants included twenty-four young people (four from each of the six communities) selected by community leaders for their capacity and literacy skills to be local facilitators who would lead discussions and document observations in their respective villages. To ensure gender balance, we asked that community leaders each choose two women and two men as trainees. During the training workshop, we explained the auto-appraisal activities and focused on dynamic exercises and role playing that allowed participants to discuss the issues they would observe in their communities and practice how to facilitate discussions about these issues. After the workshop, we invited the two women and one of the men from each village to form facilitation teams. The village facilitators returned home with a schedule for completing auto-appraisal activities, as well as notebooks and templates for documenting the results of the auto-appraisal. They were expected to invest a couple of hours per week over several weeks, visiting neighbors and convening small meetings to gather information on the community. They each received a small stipend for the time they invested. Over the course of December 2016 and February 2017, the village facilitators carried out activities on their own with periodic visits by project technicians to discuss progress as they completed the appraisal.

The second method we introduced was participatory action research (PAR), an activity in which people work together to resolve common problems or answer shared questions $[27,55]$. In PAR activities, groups gather information, reflect on what they observed, decide whether the process should continue or whether the problem is resolved. Ideally, PAR is driven by local interest focused on a shared problem or concern, and emerges from dialogue and collective reflection and decision-making. External facilitators can provide a catalyst to initiate PAR, but participation should be motivated by local demand. The method introduces structure and processes to help participants become more conscious of how they are learning; it is also dynamic, shifting focus as new information is gathered, expanding as more people become involved and ending when participants feel they have resolved the topic or when it is no longer useful to them. 
Our approach to PAR started with additional training to introduce the new concepts to the villagers and technicians supporting them. The PAR training commenced in November 2017 , building on the village auto-appraisals completed earlier in the year. We needed to train project technicians to facilitate a process of participatory experimentation by adopting a "learning-by-doing" approach. This meant that as soon as technicians learned basic concepts, they would guide others in learning the concepts, and in turn, those people would guide others. As an example, we focused on building mapping skills. In this activity, the technicians would teach villagers to use compasses, cartesian coordinate systems and GPS devices using a hands-on method that allowed participants to figure out basic functions of the tools to solve problems. As part of this training exercise, technicians organized half-day practice sessions in each of the six villages. A total of 66 villagers participated, $40 \%$ of whom were women. After the half-day course, groups from each village were loaned equipment so that over the following week they could practice by using the tools to update the sketch maps from the auto-appraisal exercises by adding georeferenced points marking relevant sites in their communities. The training was followed by a debriefing workshop that convened participants from the six villages to evaluate the exercise, to provide feedback to the technicians and to share their geo-referenced sketch maps with others. The meeting drew 56 villagers, with women making up half of the group.

The PAR activities were initiated in 2018. The WAFFI technicians convened meetings in each village to form "PAR groups" of interested community members. The first activity was to reflect on the auto-appraisal process, with the goal of deciding on village priorities they wanted to examine. In all cases, participation was voluntary and no monetary incentives to participate were provided. While the PAR activities were taking place, a small team of three WAFFI technicians rotated throughout the villages, making periodic visits to provide support and to facilitate discussion and reflection on the PAR process. The topics selected for PAR by each village group varied and changed over time, as will be discussed in the next section.

The third method we implemented were dialogue platforms for community members to exchange and compare results and define common issues. Both the auto-appraisal and PAR activities functioned as a scaffold to build knowledge to prepare for presentations and discussion at these platforms. The WAFFI project included two types of knowledge sharing events: village exchange workshops and multi-stakeholder workshops. The village exchange workshops focused on residents from selected sites, allowing villagers to present results from participatory activities, followed by discussions to compare differences, identify common issues and synthesize shared understanding. The multi-stakeholder workshops convened village representatives as well as customary leaders, government officials, NGO representatives and researchers to discuss issues in a broader context.

The WAFFI team convened the first village exchange workshop in May 2017 at the completion of the auto-appraisal studies. In this two-day meeting, community facilitators met in Paga, the district capital, and with the support of the WAFFI team, prepared presentations of the information collected during the appraisals from the sketch mapping exercises, the historic timelines and the descriptions of the five capitals. During multiple sessions, the village facilitators presented their results and discussed the similarities and differences, as well as the implications in terms of community strengths and weaknesses. A second Village Exchange Meeting in May 2018 in Navrongo, the municipal capital, focused on presenting and reflecting on the first round of PAR work. Representatives from the six communities presented summaries of their PAR work and their reflections on the issues. CIFOR and ICRAF researchers also presented observations from their research in these landscapes. Traditional chiefs attended the second day of the meeting.

Village exchange meetings helped participants prepare for multi-stakeholder workshops, which provided opportunities for community members to present syntheses from the participatory work to traditional leaders, NGO representatives and local government authorities and to discuss the broader context of the findings in a group setting. The WAFFI team convened an initial multi-stakeholder meeting to review progress in project activi- 
ties and initial results from the project following the first village exchange workshop in May 2017. Participants included the village facilitators, community leaders such as chiefs, paramount chiefs and assemblymen, and representatives of government agencies including the Forestry Commission, the Department of Agriculture and the Environmental Protection Agency. After the village facilitators presented summaries of the six auto-appraisal studies, and the CIFOR-ICRAF researchers presented work they had completed, the participants formed mixed break-out groups that included villagers, traditional authorities, researchers and governmental representatives. Distinct groups discussed issues ranging from food security to women's land and resource access rights, local issues that emerged from the community work.

The second Multi-Stakeholder Dialogue Workshop was held in February 2019 and was attended by 50 policymakers, researchers, authorities, traditional leaders and community PAR members. The format of the workshop was oriented towards group discussion, perspective-sharing and problem solving. Community representatives presented findings from their PAR projects, and researchers presented results from their studies.

During field activities, the project's technicians collected information on the number of individuals attending, participants' gender, whether they were new or repeat participants as well as observations about their roles in activities. In addition to the outcomes of these engagement processes, the technicians also observed and qualitatively documented reflections by participants about the activities. They compiled these notes and together prepared biweekly reports that were reviewed with supervisors to identify key messages to share with PAR groups to help them reflect on the process. It is important to note that our participatory methods centered on facilitation and group observations of dynamic learning processes that occurred during the dialogue-building and engagement processes.

Project workshops were also opportunities for documenting the process. The authors used participatory observation methods to interact with the village representatives taking notes during discussion groups. The proceedings were recorded and transcribed, and the discussions were systematized and coded to identify themes, participants' perspectives and priorities. At the end of each workshop, participants filled out evaluation forms and left written reflections on the workshop discussions and process. Quotes that reflected those perspectives were identified and coded for inclusion in workshop reports. Notes compiled by the authors during the events were reviewed during daily debriefs and organized to generate an account of group discussions, including paraphrased quotes from participants. After each event, a draft workshop report was circulated among the team to review for accuracy.

\section{Results: The WAFFI Approach Explained as Three Stages}

The results from the WAFFI participatory approach are presented as three stages to illustrate how social learning processes were initiated and evolved during project activities over three years. In these stages, participants were introduced to concepts and approaches through training and practical experiences. As they gained confidence with the methods, participants played more proactive roles in focusing on observations and facilitating the learning. By exchanging observations and ideas with each other and among villages, the activities coalesced around common themes and discussions of possible solutions. A main outcome of this work was that participants were able to articulate a series of action points they could communicate to policy makers that reflected common concerns of people across the project sites.

\subsection{Stage 1: Introduction of Approach and Practical Training in Auto-Appraisal}

The first stage in the WAFFI approach introduced key concepts and methods through training and practical experience to lay a foundation for the later stages. Activities started with an auto-appraisal training workshop that targeted not only village representatives who would serve as facilitators for the auto-appraisal work, but also technicians from local NGOs who would support the village facilitators (as the methods and concepts were new 
for them too). Most of the young men had participated in meetings outside their villages before but usually as passive observers; the young women had less experience, and we observed that at first, they engaged timidly. Over the course of the workshop, participants gained confidence speaking publicly, particularly the young women, who appeared to find strength in numbers when disputing men's descriptions of village life. This corroborates findings by Agarwal [56] that women are more likely to participate when more women are present.

The initial training was followed by fieldwork for the auto-appraisal studies. Periodic guidance from the WAFFI team was crucial to support the facilitators; otherwise, results were sometimes incomplete, or completed in a rote manner, missing opportunities for learning and engagement. This reminded us that "the learning way is easier said than done" [57]. Finally, this stage concluded with a village exchange workshop to share observations and a multi-stakeholder forum that allowed representatives from participating villages to share findings with local policy makers.

The landscapes described by the facilitators during the exchange depicted several environmental and socio-economic challenges, but aspects of the local context and institutional factors also illustrated the resilient character of these farm-forest systems. Initially, the themes that emerged were diverse and discussed in relatively gender-neutral terms. Facilitators observed resource degradation in their villages. For example, several reported that the loss of soil fertility was widespread, and while off-set by the use of chemical fertilizers, not all could afford such inputs. Most households farmed small plots (two to four hectares), often as sharecroppers working for local landlords. In one village near the border, the traditional farmlands of some families extended into Burkina Faso, but recently the governments began to enforce the international boundary, which meant that families lost access to arable land. In all the villages, women depended on husbands or other males to access land and explained that they were often allocated the least desirable land as men retained the best land for cash crops. However, village facilitators reported that norms were shifting, and women could enter sharecropping agreements on their own, without reliance of male relatives. In group discussions, participants did not agree why roles were changing, and it was not clear whether it was a prevalent change, but the debate nonetheless indicated that shifts were taking place. Women's crops were primarily for household consumption and were crucial for domestic food security. Trees and tree products from species including shea, baobab and African locust bean provided important subsidies for household subsistence and income. Households relied on fuelwood for cooking but competition with commercial wood and charcoal sellers had led some desirable fuel species to become scarce. Villagers reported that bushfires during the dry season were becoming more frequent and intense. Locals attributed this to changing rainfall patterns and climate change, but also reported that some fires were deliberately set by hunters and fuelwood collectors. The fuelwood collectors used fire to clear brush making it easier to locate wood on the ground, but informants suggested that some short-sighted actors also hoped to kill trees, as they were allowed to collect deadwood but could not cut live trees particularly in the gazetted forest reserves.

There were several important results from this initial stage. The auto-appraisal methods provided participants with a systematic approach to collect observations about their home villages and document perceptions for later discussion; they learned new skills and an approach to observing and sharing information with others. The process facilitated discussions first among neighbors in their village and then with residents of other villages. Furthermore, the knowledge-sharing exercises helped participants define more explicitly not only the common problems they faced but also collective strengths present across the villages. Finally, as evident by their presentations to the larger group, the village facilitators gained confidence, especially the young women involved in the activity. In the villages, women - particularly young women-have traditionally been discouraged from speaking in front of men and prohibited from participating in key decision-making [40]. However, the auto-appraisal activities elevated their status by recognizing them as leaders 
of a knowledge-gathering process that entailed conversing with important local knowledge keepers. Preparing their presentations together gave village facilitators confidence in their ideas and in themselves; others have noted the importance of investing in preparation for meetings among women and the rural poor [8]. Local leaders commented that they were impressed with the confidence of young women speaking publicly. One facilitator mentioned that she had never spoken in the presence of a chief before but now she was comfortable talking in front of multiple chiefs and other authorities; another facilitator wrote in the meeting evaluation that "my mates are bold enough to present our group work and now we believe in each other".

\subsection{Stage Two: Expanding Practical Training and Building on Knowledge Sharing}

The second stage built on the auto-appraisal experiences by introducing participatory action research (PAR) approaches with additional training exercises, village exchange meetings and a multi-stakeholder workshop.

\subsubsection{Participatory Action Research}

The PAR concepts were new to the WAFFI technicians, so it was necessary to train them in PAR methods to develop skills to facilitate processes of participatory experimentation using a "learning by doing" approach. In a train-the-trainer structure, we taught technicians to guide others in learning participatory mapping techniques, and then organized practice exercises in the six villages where the WAFFI team could train villagers in the same techniques. Activities started by asking participants "How do you explain directions?" and "How do you find your way in an unfamiliar place?" Most of the villagers had never held a compass before, so technicians shared these skills and guided participants in hands-on activities to learn what these tools were and how to use them. Participants then learned how to direct others to move to specific locations on a 10 by $10 \mathrm{~m}$ grid laid out on the ground by describing the coordinates and helped them to associate this experience with the Universal Transverse Mercator (UTM) system. With knowledge acquired from these activities, the training then focused on the basic function of GPS devices, to allow village trainees to take datum points and navigate to specific locations using the UTM coordinates. After the basic training, the WAFFI technicians loaned equipment to village participants to practice over the following week, allowing them to georeference key locations on their sketch maps from the auto-appraisal. The training concluded with a meeting that convened all participating villagers in the town of Chiana to review what they had learned, to share their georeferenced sketch maps and to provide feedback to the WAFFI technicians who had facilitated the training. The objectives were to teach a collaborative information collection method and demonstrate "learning-by-doing", an essential approach for PAR. The mapping activity generated interest and excitement because of the hands-on learning of technical skills—such as using a GPS and mapping coordinates-combined with group reflection on the process. Furthermore, the villagers learned useful participatory mapping skills that they could choose to draw upon for their PAR work.

The PAR topics that groups selected were diverse, ranging from loss of free-ranging livestock in parklands and loss of crops in irrigated land invaded by cattle to resource conflict with forest guards and access to arable land. The WAFFI technicians assisted the PAR groups in transforming these topics into research questions and deciding on the methods to use, such as mapping, simple data collection sheets or small group discussions. In one site, women were concerned about the scarcity of fuelwood near the village, so they requested use of a GPS to measure the distance they walked to gather wood. In another, the PAR group examined land scarcity by canvasing households to identify how many had farmed away from the village during the previous year using land in other communities. The PAR groups collected information that could answer questions related to their topic and met weekly to discuss results and decide on next steps. These groups were fluid, starting small with four to six members but sometimes attracting $50+$ participants to 
meetings. Nonetheless, having a core group of active members at every stage provided continuity for the process.

\subsubsection{Village Exchange}

The initial results from PAR activities in each of the villages were presented during the second village exchange workshop. The discussions focused on conditions observed in the village, but the issues began to have notable gender components with women leading some of the initiatives. For instance, two village groups measured the distances women walked to gather fuelwood, in some cases as far as $10 \mathrm{~km}$ due to scarcity. Discussions focused on why fuelwood sources were increasingly distant. One reason observed was that farmers were moving farther from villages out into parklands to find arable land for agriculture, which meant the woody debris left from clearing fields, a common source of fuel, was not found near the villages. Villagers also noted that more people were relying on the sale of firewood and charcoal as a source of income. Some men were collecting firewood in large quantities to sell to merchants with trucks, or were felling trees to produce charcoal for sale, exacerbating fuelwood scarcity. In some cases, fires were being set deliberately to kill trees, so that they could then be collected for firewood, thus skirting the prohibition against cutting live trees. In one village, women had been traveling through a forest reserve to collect firewood and had been sanctioned by forest guards, even though this practice was allowed. The women reported that they were afraid to confront the issue individually; however, in a group setting, they more freely discussed the problems they were encountering.

Overall, discussions highlighted patterns of resource degradation across the villages. Participants noted several factors impacting the trees valued for non-timber forest products (NTFPs) by women in the communities. This was particularly true for shea trees: not only would wildfires kill or damage shea trees but, depending on when they occurred, fires could cause the shea trees to abort their flowers, lowering the production of fruit. In addition, shea wood was sometimes cut in parklands because it produces high quality charcoal and is one of the locally preferred varieties. At the same time that shea resources were under stress, women also reported that, due to the increased demand for shea nut, men were getting involved in shea collection and exerting increased control over shea access. In contrast to shea in the parkland commons, shea trees on farmland tend to be closer to homesteads and are not open-access, making them easier to harvest and more productive. Furthermore, because farmland is managed more intensively, shea trees suffer less damage from wildfire. The men present at the exchange meeting denied any involvement but were met with strong rebukes from the women. Because women do not own land, they said they were increasingly dependent on going to the parkland commons or to the forest reserves to collect shea. However, conflicts with forest guards were growing, since access rules for forest products were unclear. This village exchange meeting, and the interest it generated, proved to be a catalytic point of entry for later PAR work and social learning on shea nut and gender, which ultimately led to shifts in thinking about women's and men's roles in shea nut activities.

Based on these discussions, village participants agreed that the following round of PAR activities would target factors affecting the NTFPs important to women as well as issues related to land access and wildfire. The participants identified opportunities to address these issues, such as strengthening internal rules for resource use, encouraging enforcement by local committees and connecting with forestry officials to clarify access rules. At the close of the workshop participants expressed interest in focusing PAR activities to track issues around resource governance, NTFPs, fuelwood and wildfires.

\subsection{Stage 3: Practical Exercises Coalesce around Common Concerns}

As noted above, during the first round of PAR work, one emergent issue was the conflicting perspectives on the role of men in shea collection. Women in several communities claimed that men were excluding them from the most productive on-farm trees, taking 
an important income source from women. Men were reluctant to admit any involvement as shea is considered women's work. After the exchange workshop, an interesting PAR dynamic developed.

In the community where the debate over the involvement of men first developed, women decided to refocus their PAR groups on monitoring their shea nut collection activities. With assistance from WAFFI technicians, they developed a simple monitoring system in which each day, using a simple tally sheet with pictures and diagrams, the women could check boxes to record whether they had harvested shea, where they harvested (i.e., farm, fallows, forest commons or reserve forest) and how much they had harvested. Initially, thirteen women in the PAR group in one village began monitoring their shea harvests. At the end of the week, the WAFFI technicians returned to the village to help the PAR members review the results and discuss their experiences. The team also prepared visual aids, such as charts and graphs, to illustrate observations about the data and encourage discussion (see Figure 3 for an example).

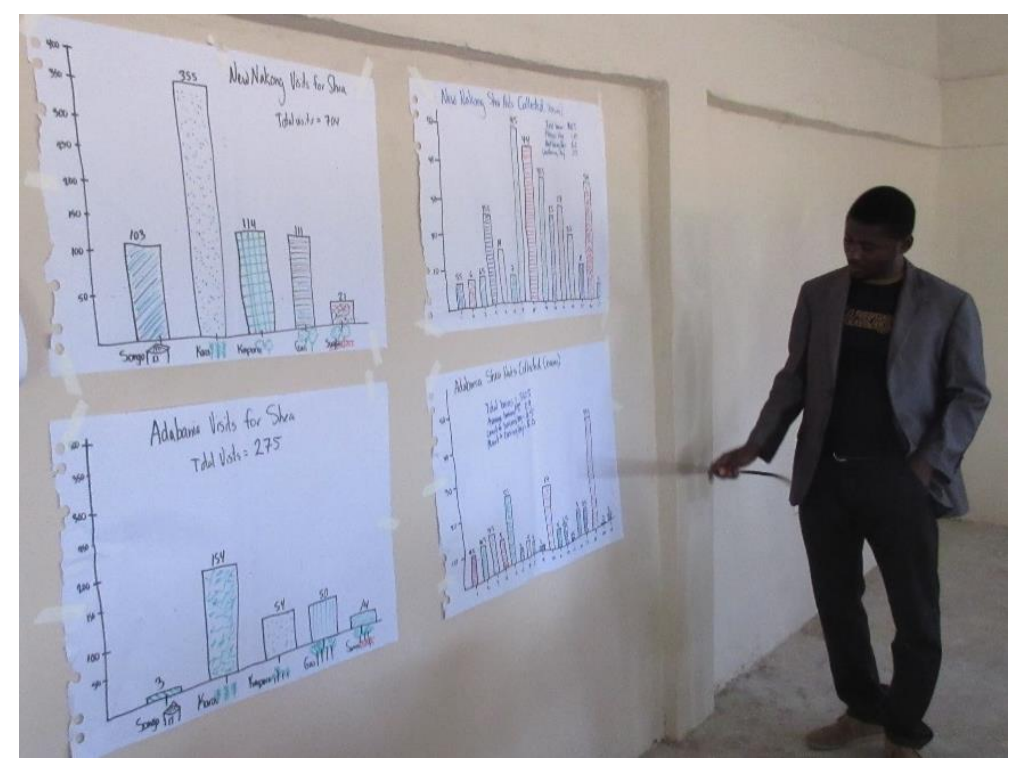

Figure 3. A team technician presents the information collected by the participants with visual aids.

More women became interested in the activity and after three weeks, 32 women had monitored at least one week of shea harvests. The tally sheets that were collected by the PAR group recorded 308 instances where women had recorded their daily harvests. Surprisingly, on $60 \%$ of these days, women were gathering shea on farm sites. As the project technician asked probing questions to reflect on the results, the women explained that they were still harvesting shea on the family's farmland, but their husbands were claiming a larger share of what the women harvested for themselves. The WAFFI technicians showed the charts illustrating results from the shea monitoring to PAR groups in other villages, and local women in two other villages also began tracking shea harvests and similarly noted about $50 \%$ of the days monitored included harvests from shea trees on farmland.

PAR group members in all six villages collected data on shea collection from JuneAugust 2018. It is important to note that these monitoring processes were oriented towards engaging people in the process and collecting sufficient information about the situation to encourage reflection and discussion; the activities were not intended to be precise data collection methods. As others have argued, participatory monitoring learning cycles are best facilitated by data collection that is adequate to answer people's questions, not necessarily following rigorous scientific methods [58].

The WAFFI technicians regularly visited each village approximately every three weeks to convene report-back meetings to check on progress and lead a guided reflection on the results since the previous meeting. The data collection was carried out by the participants, 
on their own schedule, with only periodic check-ins by the WAFFI technicians. The process generated substantial interest, and attendance at each meeting grew as the PAR process honed the questions during each phase and generated results, as can be seen in Figure 4, which sums the participants from all villages at each of the eleven rounds of meetings held with each village, disaggregated by gender. Furthermore, the proportion of women participating increased significantly during the second phase of the PAR work, which focused on shea. This decision to focus on shea resulted from the interest expressed by several groups of women in the villages, and it notably demonstrates how participation reflects the interests and priorities of the participants. In other words, when the topic matters to women and their opinions are prioritized, they engage. Of the 412 people who attended at least one PAR meeting in one of the six villages, $67 \%$ of these unique participants were women. As noted before, participants were not paid, so the motivation to participate can reasonably be attributed to interest in the activity itself.

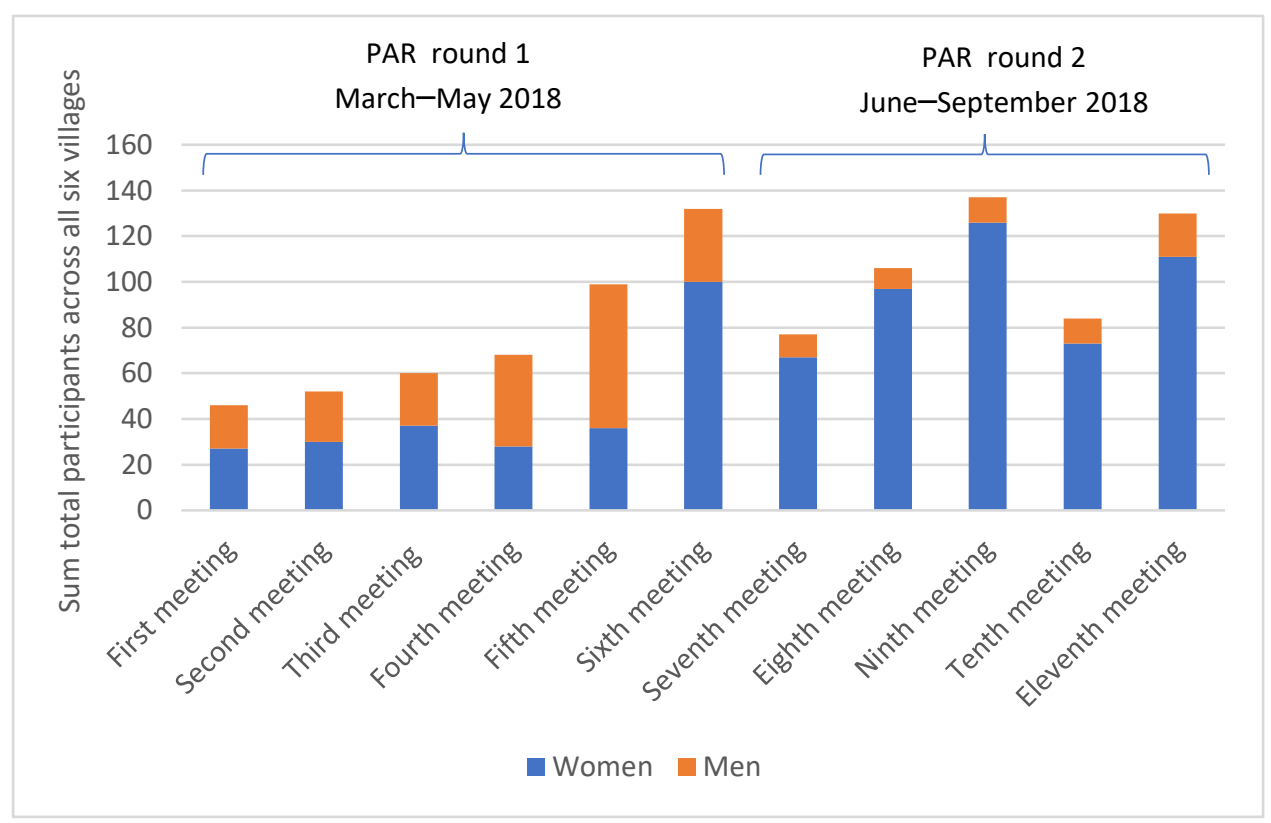

Figure 4. Participation in participatory action research (PAR) meetings by gender. Totals for each meeting illustrate the sum of unique and repeat participants across six villages.

The discussions revealed that shea access issues were more complex than men simply excluding women from the resource. Surprisingly, although women had argued that they were being excluded from on-farm shea, they still reported frequent harvests of shea from on-farm trees, equivalent to roughly half of the reported harvests. However, when discussing these results, women explained that while they were still harvesting from shea trees in farm fields, men were now frequently claiming the fruit and only providing a share to the women. In other words, women were being excluded not from the working with the resource, but from the income. The women knew this, but the monitoring activity allowed them to better enunciate the issue and illustrate how this was a shared problem. The change in control over on-farm shea income was occurring because buyers had started purchasing shea nuts directly in the villages. Traditionally, there had been a stigma to men selling shea nuts or shea butter in markets, so the products were considered within the women's domain. As demand for shea increased, women were losing control over an important source of income. These results illustrate that access rights are nuanced and context-specific; rights are constantly negotiated at the family level and community level as well as in other spheres as a part of everyday life and practice. 


\section{Final Workshop}

During the final multi-stakeholder workshop, discussions focused on issues that emerged from the research, particularly three crucial topics: shea access and management, fuelwood and bushfires. Themes that emerged across these topics included discussion of women's access to land and how traditional land distributions systems were changing. Customarily, women did not own land but received access through their husband or other male relative, or in some cases had their husbands request land from a landlord. More recently, in some cases, women no longer needed their husbands to act as intermediaries to request land but could do it themselves. There was also discussion of women's dependence on NTFPs and their increasing reliance on forest reserves as their access to shea nut income on farms was constrained. Small groups discussed the findings, identified problems and issues and defined strategies and paths forward.

The participants proposed several integrated visions and strategies to combine community, policy and research approaches:

- Strengthen women's influence and opportunities-Women depend on shea to feed their families and as a source of income; as a result, they are key actors in shea management. However, changing conditions were pressuring women from multiple angles. Participants in the workshop advocated for improvement in women's access to shea at the household level by opening dialogue on the effects of change. There was a suggestion that efforts were needed to organize local cooperatives to provide loans and procure shea processing machinery to allow women to add value more efficiently to their harvest and create additional livelihood opportunities. There was also interest in continuing actively to engage more directly in governance processes at multiple levels by encouraging more women to stand for both political and community leadership positions.

- Develop the shea sector-Despite the importance of shea in the region, there was the perception that the sector lacked organization, coordinated planning or development strategy. Participants suggested lobbying to form an advocacy group, possibly at the national level, such as a "shea board", that could influence policy, promote shea, define strategies and address challenges. In addition, promoting shea research to investigate topics related to shea production, protection and regeneration could provide valuable support to the sector and respond to problems observed by producers.

- $\quad$ Reduce the pressure on tree resources-Participants agreed that there should be efforts to promote methods and technologies to reduce pressure on shea trees. For example, use of improved cookstoves or alternative fuels could decrease the demand for charcoal. Encouraging efforts to produce fuelwood species, either through farmer managed natural regeneration or family woodlots with fast-growing charcoal species could provide alternatives, as could introducing livelihood alternatives for charcoal producers so that individuals are not pushed to fuelwood sales as their only option for income generation. As mentioned above, the policies and plans to protect shea trees and promote shea regeneration are important but would be more effective with alternative fuel options.

- Approach bushfire management holistically-Participants advocated for approaching bushfire management at both the policy level and the community level by developing "bottom up" bylaws starting at the community to address bushfires and empowering chiefs to enforce the bylaws. Furthermore, cross-boundary strategies needed development as well as capacity to address issues of fire prevention, education and enforcement.

\section{Discussion}

\subsection{A Change in Understanding at Multiple Scales}

In the previous sections we presented the implementation of a participatory approach that we believe successfully facilitated social learning among residents of six rural villages in northern Ghana. In this section, we re-examine some aspects of the approach to identify 
factors contributing to social learning and why we feel the approach could be valuable for development initiatives.

As described in the introduction, Reed et al. [34] identified three conditions for social learning to occur: first, demonstrate a change in understanding among the individuals involved; second, that the change occurs in a wider social unit or community; third, that the change in understanding occurs through social interactions or processes. While we agree with Scholz et al. [33] that participatory methods do not automatically generate social learning, we observed all three conditions over the course of applying the participatory approaches as described. The experience increased understanding among individual village participants by assisting them in systematically observing local environmental and production conditions and facilitating discussions among neighbors. During this process, they shared information and collectively reflected on results within and among village groups and ultimately with external authorities. The entire process involved social interactions in the collection of information, evaluation of that information and discussions of its implications. Furthermore, the process improved understanding about issues crucial to the villagers and generated new knowledge collaboratively, bringing to fore the following issues:

- Increased market demand for shea was shifting patterns of resource access and benefits, a change that merited more attention by villagers and development actors. Specifically, women were reportedly losing control over income from some of the most productive shea trees as some men claimed shea nuts or derivative income for themselves. Women reported the loss of access as they became increasingly reliant on more distant and degraded resources in communal parkland or forests reserves. They reported that the loss of income negatively impacted household wellbeing, as it had supported domestic needs and food security.

- As mentioned above, shea resources were reportedly being degraded in communal parklands and forest reserves despite the increased value of the resource. Weak governance and control in these collective areas reportedly permitted near openaccess conditions that discouraged better management of trees and seedlings. As a result, fire damaged shea trees or suppressed regeneration or in some cases trees were cut for fuelwood and commercial charcoal production. In general, both customary and formal rules to better protect shea trees in these landscapes were lacking.

\subsection{A Scaffold to Strengthen Women's Capacity to Participate in MSFs}

The WAFFI process functioned as a participatory scaffold to build capacity to participate in multi-stakeholder forums. The auto-appraisal process grounded the participantsboth the villagers and the WAFFI team-in the context by providing an immersive process to systematically reveal and document aspects of the local reality. It also built common ground in understanding together the issues that the communities were facing. The PAR work generated useful information that villagers contributed to discussions. The activities gave people confidence and skills to present their opinions. Others have found that low confidence in a group setting and lack of presentation skills can be major barriers to rural women's participation [7,9].

The WAFFI participatory approach unfolded over three years, and the impacts in terms of strengthening women's confidence and capacity were incremental, yet palpable both to the participating women and to the community leaders and chiefs who witnessed the changes. Rist et al. [22] argue that this kind of interaction among experts and local people produces joint knowledge that is crucial to improving the capacity of rural communities to define their own interests, acquire new knowledge and mobilize resources that can help them catalyze changes that are in line with their own vision and needs. These types of multi-year investments in strengthening capacity are necessary to level the playing field for women and other under-represented groups in MSFs. MSFs are growing increasingly important as mechanisms for expressing opinions and values that are folded into policy [6]. Like all political arenas, the format and content of MSFs are 
determined by and dominated by those already in power, whether they are government officials, external donors or NGOs [9]. If MSFs are to meet their potential for broadening participation in decision-making and democratizing policy development, then a concerted effort is needed to implement mechanisms that level the playing field for less powerful stakeholders. Strengthening capacities such as presentation skills, information collection and community organizing are the types of bottom-up efforts and investments that will reinforce top-down mandates such as quotas. In fact, we instituted quotas at the outset when we insisted that each village facilitation team include both females and male members during the auto-appraisal process, which made it more socially acceptable for the women to participate and travel. The high percentage of female facilitators generated an environment of greater participation by the village women. This confirms findings by Agarwal [56] that rural women are less likely to be reticent and more likely to overcome restrictive social norms when other women are present.

\subsection{Encouraging Women's Engagement}

Given the central role of women in forest resource use in dryland forests of subSaharan Africa and the obstacles to their participation from the local patriarchal traditions, the WAFFI project took conscious steps to include women and prioritize their knowledge and opinions. We explicitly invited women and set quotas for their participation, and we organized meetings in villages and at time/locations that were accessible for them. We welcomed mothers to bring their children, and we accommodated them when they did, in one instance watching the children so that the mothers were free to do mapping activities. Finally, we set up special times to prepare for exchange meetings so that women could build their presentation skills and confidence to participate in public meetings.

Encouraging women's engagement in the activities extended to the selection of research topics. The high levels of women's participation meant that the PAR work often focused on issues important to women, including the added burdens they face with depleting fuelwood stocks, conflicts over use of key NTFPs and difficulties women face due to shifting resource access rights driven by change in market conditions. The PAR approach also responded to the unique challenges that women face when voicing their opinions. For instance, when the women were afraid to tell the truth about collecting firewood from the forest, PAR provided a method to explore why and learn more about the issue. Women felt strength in numbers when they met as a large group, and they openly discussed the issues with WAFFI technicians and researchers. This provided an evidence-based process for gender transformative action.

Outside facilitation can be necessary to creating the conditions for gender transformative action [8], and training facilitators in participatory methods requires hands-on experiential learning too. The WAFFI approaches were not familiar to local collaborating partners and technicians, who had been trained in conventional approaches to extension. This required considerable time for training and follow-up, regular visits to the field and workshops to train local field team and partners in how to use the approaches appropriately. While the methods were not particularly complicated or difficult, they did require people to change their approaches and to be self-aware of their roles. Some people may resist these approaches because they do not see the value or the focus on community knowledge undercuts their status. Nevertheless, the interaction between outsiders and local people can play a key role in highlighting gendered social norms, expectations and assumptions. For instance, when a local male technician was asked prior to the village facilitator training if the female village facilitators processed shea nut, he said that they did not, because of their levels of education. When the female village facilitators were subsequently asked the question, they laughed and said, "We all do!" People are often unaware of gender frameworks until they are pointed out to them. 


\section{Conclusions}

Smallholder systems found in semi-arid savanna landscapes in northern Ghana combine crops, livestock, forests and trees in complex mosaics adapted to local conditions. The acquired knowledge of producers living in the rural spaces provides a foundation for the resilience of these systems, but constant change requires continuous learning processes. Women play integral roles in these dryland systems, particularly in the management of trees, which are important components of their livelihoods. However, customary systems of land and tree tenure differentially constrain women's access to resources, while national policies do not acknowledge or support their roles as resource managers. Creating conditions that allow women and men to share their experiences and contribute to development dialogue will help communities to react to and prepare for change.

In the research presented here, we used participatory approaches to improve engagement and influence of underrepresented people, especially women, in dialogue and decision-making. This approaches consisted of three nested activities to facilitate inclusion and build social learning processes: auto-appraisal, participatory action research (PAR) and exchange workshops held at the village and district level. In these stages, participants were introduced to concepts and approaches through training and practical experience. As they gained confidence with the methods, they played more proactive roles in focusing on observations and learning. By exchanging ideas with each other and among villages, the activities coalesced around common themes and discussions of possible solutions. The objective was to encourage grassroots dialogue and broad participation to build consensus around common issues and shared problems to strengthen the capacity of local people to ensure that their interests were addressed by decision makers. We argued for a bottom-up approach for promoting greater inclusion by women, an approach whereby opinions, attitudes and frames of reference about gender were shifted and reframed at the individual and community levels through group learning processes known as social learning.

The social learning processes translated into several palpable shifts in gender perspectives. For instance, when women were challenged about their claims that men were getting involved in shea, they responded by collecting data to prove their point, which they presented at the final multi-stakeholder workshop. Men were surprised by the data, but they accepted it. While this might not seem to be a major change, it is an opening nonetheless, and women who participated in the WAFFI process are better prepared to negotiate within these new spaces. Furthermore, there were indications that these changes were happening within a larger context where gender roles were shifting, in terms of access to resources and livelihood activities; understanding these shifts is an area that merits future research.

Participatory approaches can be time-consuming and resource intensive but if implemented effectively, they can generate social learning processes. The WAFFI approach demonstrated that social learning processes can improve the influence of women and under-represented groups in MSFs and other decision-making platforms. Top-down mandates, such as quotas, can work hand-in-hand with social learning to shift perspectives on gender, establish role models and create environments where the opinions and priorities of women are given the same weight as those of men. The participatory activities generated iterative cycles of local knowledge assessment and group learning that built on a stepwise process of observation, analysis, planned action, monitoring and reflection. These methods facilitate women's engagement in natural resource management dialogues to give voice to their priorities and frame debate around topics important for their livelihoods. A main outcome of this work was that participants were able to articulate a series of action points they could communicate to policy makers that reflected common concerns of people across the project sites.

Author Contributions: Formal analysis, P.C., K.E., T.A., E.S.D. and M.Z.; Funding acquisition, P.C.; Investigation, P.C., K.E., T.A., E.S.D., M.Z. and H.D.; Methodology, P.C., K.E. and E.S.D.; Supervision, P.C.; Writing-original draft, P.C. and K.E.; Writing—review \& editing, T.A., E.S.D., M.Z. and H.D. All authors have read and agreed to the published version of the manuscript. 
Funding: This research was funded by International Fund for Agriculture and Development (IFAD), grant number 2000000995. The research also received funding support from the CGIAR Research Program on Forest, Trees and Agroforestry (FTA).

Institutional Review Board Statement: The activities described in this paper followed protocols established by the Declaration of Helsinki with regard to informed consent, vulnerable groups and individuals, confidentiality of data and other requirements. During fieldwork, verbal prior informed consent was received in English and the local Kasem language, and individuals were informed that participation was voluntary and that they could cease participation at any time.

Informed Consent Statement: Verbal informed consent was obtained from subjects participating in the activities described in this paper. All participants were informed in English and in Kasem (language of the Kassena ethnic group) that participation was voluntary, and they could end participation at any time. Contact information for project staff in Ghana was left with village leaders as was contact information for CIFOR and ICRAF offices in Ouagadougou, Burkina Faso.

Acknowledgments: We are grateful to the village participants in the WAFFI project in Ghana and Burkina Faso who provided their enthusiastic assistance and invaluable knowledge in this process. We also thank our partners Tree Aid and ORGIIS for their contributions. We thank the International Fund for Agriculture and Development (IFAD) for funding the WAFFI project.

Conflicts of Interest: The authors declare no conflict of interest.

\section{References}

1. Cronkleton, P.; Larson, A.M.; Feintrenie, L.; Garcia, C.; Levang, P. 2013 Reframing community forestry to manage the forest-farm interface. SmallScale For. 2013, 12, 5-13.

2. Agrawal, A.; Wollenberg, E.; Persha, L. Governing agriculture-forest landscapes to achieve climate change mitigation. Glob. Environ. Chang. 2014, 29, 270-280. [CrossRef]

3. Carney, J.; Elias, M. Revealing gendered landscapes: Indigenous female knowledge and agroforestry of African shea. Can. J. Afr. Stud. Rev. Can. Études Afr. 2006, 40, 235-267. [CrossRef]

4. Boakye, K.A.; Baffoe, K. Trends in Forest Ownership, Forest Resource Tenure and Institutional Arrangements in Africa. In FAO Regional Workshop - A 2006 Case Study from Ghana; Food and Agriculture Organization of the United Nations: Nakuru, Kenya, 2016; p. 151.

5. Beisheim, M.; Simon, N. Multi-Stakeholder Partnerships for Implementing the 2030 Agenda: Improving Accountability and Transparency. In From Commitments to Results: Leveraging Partnerships for the 2030 Agenda. In Proceedings of the 2016 ECOSOC Partnership Forum, New York, NY, USA, 31 March 2016; Social Science Research Network: Rochester, NY, USA, 2016.

6. Barletti, J.P.S.; Larson, A.M.; Hewlett, C.; Delgado, D. Designing for engagement: A Realist Synthesis Review of how context affects the outcomes of multi-stakeholder forums on land use and/or land-use change. World Dev. 2020, 127, 104753. [CrossRef]

7. Nuggehalli, R.K.; Prokopy, L.S. Motivating factors and facilitating conditions explaining women's participation in co-management of Sri Lankan forests. For. Policy Econ. 2009, 11, 288-293. [CrossRef]

8. McDougall, C.L.; Leeuwis, C.; Bhattarai, T.; Maharjan, M.R.; Jiggins, J. Engaging women and the poor: Adaptive collaborative governance of community forests in Nepal. Agric. Hum. Values 2013, 30, 569-585. [CrossRef]

9. $\quad$ Evans, K.; Monterroso, I.; Bwire, D.; Liswanti, N.; Tamara, A.; Mariño, H.; Sarmiento Barletti, J.P.; Larson, A.M. Getting it Right: A Guide to Improve Inclusion in Multi-Stakeholder Forums; Center for International Forestry Research (CIFOR): Bogor, Indonesia, 2021.

10. Wagle, R.; Pillay, S.; Wright, W. Examining Nepalese Forestry Governance from Gender Perspectives. Int. J. Public Adm. 2017, 40, 205-225. [CrossRef]

11. Cook, N.J.; Grillos, T.; Andersson, K.P. Gender quotas increase the equality and effectiveness of climate policy interventions. Nat. Clim. Chang. 2019, 9, 330-334. [CrossRef]

12. Beaman, L.; Duflo, E.; Pande, R.; Topalova, P. Female Leadership Raises Aspirations and Educational Attainment for Girls: A Policy Experiment in India. Science 2012, 335, 582-586. [CrossRef] [PubMed]

13. Muriaas, R.L.; Tønnessen, L.; Wang, V. Exploring the relationship between democratization and quota policies in Africa. Womens Stud. Int. Forum 2013, 41, 89-93. [CrossRef]

14. Bose, P. Land tenure and forest rights of rural and indigenous women in Latin America: Empirical evidence. Womens Stud. Int. Forum 2017, 65, 1-8. [CrossRef]

15. Evans, K.; Larson, A.M.; Flores, S. Learning to learn in tropical forests: Training field teams in adaptive collaborative management, monitoring and gender. Int. For. Rev. 2020, 22, 189-198. [CrossRef]

16. Keen, M.; Brown, V.A.; Dyball, R. Social Learning in Environmental Management: Towards a Sustainable Future; Routledge: Milton Park, UK, 2005.

17. Kolb, D.A. Experiential Learning: Experience as the Source of Learning and Development; Pearson Education: London, UK, 2014.

18. Colfer, C.J.P. The Complex Forest: Communities, Uncertainty, and Adaptive Collaborative Management; Resources for the Future (RFF): Washington, DC, USA; Center for International Forestry Research (CIFOR): Bogor, Indonesia, 2005. 
19. Kolb, D.A.; Osland, J.; Rubin, I.M. The Organizational Behavior Reader; Prentice-Hall: Hoboken, NJ, USA, 1995.

20. Maarleveld, M.; Dabgbégnon, C. Managing natural resources: A social learning perspective. Agric. Hum. Values 1999, 16, 267-280. [CrossRef]

21. Peschl, M.F. Triple-loop learning as foundation for profound change, individual cultivation, and radical innovation: Construction processes beyond scientific and rational knowledge. Constr. Found. 2007, 2, 136-145.

22. Rist, S.; Chidambaranathan, M.; Escobar, C.; Wiesmann, U.; Zimmermann, A. Moving from sustainable management to sustainable governance of natural resources: The role of social learning processes in rural India, Bolivia and Mali. J. Rural Stud. 2007, 23, 23-37. [CrossRef]

23. Colferm, C.J.P. The Equitable Forest: Diversity, Community and Resource Management; Resources for the Future (RFF): Washington, DC, USA; Center for International Forestry Research (CIFOR): Bogor, Indonesia, 2005.

24. Guijt, I. Negotiated Learning: Collaborative Monitoring in Forest Resource Management; Resources for the Future (RFF): Washington, DC, USA, 2007.

25. Evans, K.; Larson, A.M.; Mwangi, E.; Cronkleton, P.; Maravanyika, T.; Hernandez, X.; Müller, P.; Pikitle, A.; Marchena, R.; Mukasa, C.; et al. Field Guide to Adaptive Collaborative Management and Improving Women's Participation; Center for International Forestry Research (CIFOR): Bogor, Indonesia, 2014.

26. Berkes, F. Evolution of co-management: Role of knowledge generation, bridging organizations and social learning. J. Environ. Manag. 2009, 90, 1692-1702. [CrossRef] [PubMed]

27. German, L.; Stroud, A. A Framework for the integration of diverse learning approaches: Operationalizing agricultural research and development (R\&D) linkages in Eastern Africa. World Dev. 2007, 35, 792-814.

28. German, L.; Tiani, A.M.; Daoudi, A.; Mutimukuru-Maravanyika, T.; Chuma, E.; Jum, C.; Nemarundwe, N.; Ontita, E.; Yitamben, G. The Application of Participatory Action Research to Climate Change Adaptation in Africa: A Reference Guide; International Development Research Centre (IDRC): Ottawa, OT, Canada, 2012.

29. Bandura, A. Social Learning Theory; General Learning Press: New York, NY, USA, 1971.

30. Borrini, G.; Jaireth, H.; Farvar, M.T.; Pimbert, M.; Kothari, A. Sharing Power: Learning-By-Doing in Co-Management of Natural Resources throughout the World; Earthscan: London, UK, 2007.

31. Walters, C.J.; Holling, C.S. Large-Scale Management Experiments and Learning by Doing. Ecology 1990, 71, 2060-2068. [CrossRef]

32. Rodela, R. Social Learning and Natural Resource Management: The Emergence of Three Research Perspectives. Ecol. Soc. 2011, 16, 30. [CrossRef]

33. Scholz, G.; Dewulf, A.; Pahl-Wostl, C. An analytical framework of social learning facilitated by participatory methods. Syst. Pract. Act. Res. 2014, 27, 575-591. [CrossRef]

34. Reed, M.S.; Evely, A.C.; Cundill, G.; Fazey, I.; Glass, J.; Laing, A.; Newig, J.; Parrish, B.; Prell, C.; Raymond, C.; et al. What is Social Learning? Ecol. Soc. 2010, 15, 1-10. [CrossRef]

35. Agarwal, B. Participatory Exclusions, Community Forestry, and Gender: An Analysis for South Asia and a Conceptual Framework. World Dev. 2001, 29, 1623-1648. [CrossRef]

36. Asiama, K.; Lengoiboni, M.; van der Molen, P. In the land of the dammed: Assessing governance in resettlement of Ghana's Bui Dam Project. Land 2017, 6, 80. [CrossRef]

37. Yokying, P.; Lambrecht, I. Landownership and the gender gap in agriculture: Insights from northern Ghana. Land Use Policy 2020, 99, 105012. [CrossRef]

38. Doghle, K.; King, R.S.; Akaabre, P.B. Legal establishments and gendered access to land in patriarchal societies of north-western Ghana. Afr. J. Land Policy Geospat. Sci. 2018, 1, 77-99.

39. Doss, C.R. Men's Crops? Women's Crops? The Gender Patterns of Cropping in Ghana. World Dev. 2002, 30, 1987-2000. [CrossRef]

40. Lambrecht, I.B. As a husband I will love, lead, and provide: Gendered access to land in Ghana. World Dev. 2016, 88, 188-200. [CrossRef]

41. Kansanga, M.; Andersen, P.; Atuoye, K.; Mason-Renton, S. Contested commons: Agricultural modernization, tenure ambiguities and intra-familial land grabbing in Ghana. Land Use Policy 2018, 75, 215-224. [CrossRef]

42. Adatuu, R.; Apusigah, A.A. Gender, Political Participation and Local Governance in The Builsa North District of Ghana, Ghana. UDS Int. J. Dev. 2018, 5, 181-196.

43. Doss, C.R.; Morris, M.L. How does gender affect the adoption of agricultural innovations? The case of improved maize technology in Ghana. Agric. Econ. 2000, 25, 27-39. [CrossRef]

44. Pehou, C.; Djoudi, H.; Vinceti, B.; Elias, M. Intersecting and dynamic gender rights to néré, a food tree species in Burkina Faso. J. Rural Stud. 2020, 76, 230-239. [CrossRef]

45. Kent, R. "Helping" or "Appropriating"? Gender Relations in Shea Nut Production in Northern Ghana. Soc. Nat. Resour. 2018, 31, 367-381. [CrossRef]

46. Elias, M.; Carney, J. African shea butter: A feminized subsidy from nature. Africa 2007, 77, 37-62. [CrossRef]

47. Rousseau, K.; Gautier, D.; Wardell, D.A. Socio-economic differentiation and shea globalization in western Burkina Faso: Integrating gender politics and agrarian change. J. Peasant Stud. 2019, 46, 747-766. [CrossRef]

48. Lovett, P.N.; Haq, N. Diversity of the Sheanut tree (Vitellaria paradoxa CF Gaertn.) in Ghana. Genet. Resour. Crop. Evol. 2000, 47, 293-304. [CrossRef] 
49. Lasco, R.D.; Delfino RJ, P.; Catacutan, D.C.; Simelton, E.S.; Wilson, D.M. Climate risk adaptation by smallholder farmers: The roles of trees and agroforestry. Curr. Opin. Environ. Sustain. 2014, 6, 83-88. [CrossRef]

50. Clavel, D. Vulnerability and Resilience of Smallholder Farms. In Knowledge and Rural Development: Dialogue at the Heart of Innovation; Clavel, D., Ed.; Springer: Dordrecht, The Netherlands, 2014; pp. 1-4.

51. Laube, W.; Awo, M.A.; Derbile, E.K. Smallholder Integration into the Global Shea Nut Commodity Chain in Northern Ghana; ZEF Working Paper Series; Center for Development Research University of Bonn: Bonn, Germany, 2017.

52. Taylor, P.L.; Cronkleton, P.; Barry, D.; Stone-Jovicich, S.; Schmink, M. 'If You Saw it with My Eyes': Collaborative Research and Assistance with Central American Forest Steward Communities; Center for International Forestry Research (CIFOR): Bogor, Indonesia, 2008.

53. Chambers, R. The origins and practice of participatory rural appraisal. World Dev. 1994, 22, 953-969. [CrossRef]

54. Department for International Development (DFID). Sustainable Livelihoods Guidance Sheets; Department for International Development: London, UK, 1999.

55. Borda, O.F. Participatory (action) research in social theory: Origins and challenges. In SAGE Handbook of Action Research: Participative Inquiry and Practice; SAGE: London, UK, 2001; pp. 27-37.

56. Agarwal, B. Does Women's Proportional Strength Affect their Participation? Governing Local Forests in South Asia. World Dev. 2010, 38, 98-112. [CrossRef]

57. Ojha, H.R.; Hall, A.; Rasheed, V.S. Adaptive Collaborative Approaches in Natural Resource Governance: Rethinking Participation, Learning and Innovation; Earthscan: Oxon, UK, 2013.

58. Demeo, T.; Markus, A.; Bormann, B.; Leingang, J. Tracking Progress: The Monitoring Process Used in Collaborative Forest Landscape Restoration Projects in the Pacific Northwest Region; University of Oregon: Eugene, OR, USA, 2015. 